\title{
KAJIAN PARTISIPASI MASYARAKAT DALAM UPAYA PENGELOLAAN HUTAN LINDUNG DI PASAMAN, SUMATERA
}

BARAT

\author{
(Study of Community Partisipation toward Protection Forest in
}

Pasaman, West Sumatra)

\author{
Oleh / By : \\ Bakhdal, Nani Sri Wahyuni \& Muhammad Ali ${ }^{1)}$
}

\begin{abstract}
The main function of protection forest is as water regulator and it is very important for the communities around. Some protection forests in West Sumatra get serious pressure from them, because they do not know about the borders and use some its resource. The research was conducted in Nagari Padang Matinggi and Nagar Binjai Pasaman regency, West Sumatra Province to 0 know social condition and community participation around protection forest. Data were collected by interviewing and distributing questionnaires to 60 respondents (30 respondents each village). The result of the research showed that the communities who live around the location are Minangkabaus and Mandailings, low education, low income, more than four members family, and worked as farmer. The community with strong culture showed higher participation than those with weak culture. The level participation is also effected by the project development in protection forest. If the project gives financial contribution to household, the participation will increase. Beside that, according to respondent, the protected forest is the area of their elders (ninik mamak), so they can manage the protected forest under permission from their ninik mamak only. While the government claims that the same area should be functioned as protected area. Based on this finding the government has to take an action by giving more knowledge to the community about forestry zone, so that they understand which areas are belong to them and which areas are belong to the government.
\end{abstract}

Keys words: forestprotection, community around forest, community participation

\section{ABSTRAK}

Hutan lindung berfungsi sebagai pengatur tata air, namun di sisi lain ia mendapat tekanan serius dari masyarakat sekitarnya. Berdasarkan hal ini maka perlu dilakukan kajian untuk mengetahui hubungan hutan lindung dengan kehidupan masyarakat sekitarnya. Kajian ini dilakukan di Nagari Padang Matinggi dan Nagari Binjai, Kabupaten Pasaman, Propinsi Sumatera Barat. Pengumpulan data dilakukan dengan metoda survey dengan wawancara terhadap 60 responden (kepala keluarga) masingmasing 30 orang dari setiap nagari. Data dianalisa secara tabulasi dan deskripsi. Hasil penelitian menunjukkan bahwa masyarakat sekitar hutan lindung berkultur asli Minang dan Mandailing dengan pendidikan rendah (SD), berpendapatan relatif rendah, dengan anggota keluarga lebih dari empat orang, dan bermatapencaharian sebagai petani. Pandangan terhadap hutan lindung sangat dipengaruhi oleh adat lokal yang menyatakan bahwa kawasan hutan lindung adalah wilayah ulayat. Penggunaan hutan lindung untuk kegiatan ekonomi dapat dilakukan sepanjang mendapat izin "ninik mamak", sementara dari pemerintah dinyatakan sebagai kawasan terlarang. Dualisme status kawasan ini selanjutnya menimbulkan berbagai tekanan masyarakat terhadap kawasan hutan lindung. Masyarakat di nagari yang masih kuat adatnya menunjukkan tingkat partisipasi yang lemah dibandingkan dengan yang longgar. Kekuatan partisipasi juga dipengaruhi oleh pengetahuan tentang manfaat yang diperoleh dari poyek pengelolaan hutan lindung yang dilakukan pemerintah; partisipasi akan meningkat jika proyek memberikan kontribusi finansial kepada warga setempat. Oleh karena itu, perlu dilakukan

\footnotetext{
${ }^{1)}$ Peneliti pada Balai Penelitian dan Pengembangan Kehutanan Wilayah Sumatera
} 
sosialisasi kepastian status kawasan hutan lindung pada nagari yang masih kuat pengaruh adatnya dengan mengikutsertakan "para ninik mamak" dan mempertahankan proyek-proyek yang dapat meningkatkan pendapatan masyarakat.

Kata kunci: hutan lindung, masyarakat sekitar hutan, partisipasi masyarakat.

\section{PENDAHULUAN}

Hutan lindung adalah kawasan hutan yang karena karakteristik ekosistem atau sifat alamnya diperuntukkan guna pengaturan tata air, pencegah banjir dan erosi serta pemelihara kesuburan tanah. Secara formal hutan lindung menurut Undang-undang No 41 tahun 1999 adalah kawasan hutan yang mempunyai fungsi pokok sebagai perlindungan sistem penyangga kehidupan untuk mengatur tata air, mencegah banjir, mengendalikan erosi, mencegah instrusi air laut dan memlihara kesuburan tanah. Peruntukan tersebut termasuk jenis manfaat intangible yang berasal dari ekosistem hutan lindung (Bahruni, 1992), dan manfaat ini tidak kalah pentingnya dibandingkan manfaat tangible. Menurut Badan Planologi Kehutanan (2002) dalam Anonim (2004) secara keseluruhan sisa hutan lindung di Indonesia berkisar 15\% dari total daratan; yang idealnya harus mencapai $30 \%$.

Meskipun diketahui mempunyai manfaat besar dalam mengatur tata air serta mencegah erosi dan banjir, namun demikian keberadaan hutan lindung masih belum direspon secara positif oleh masyarakat sekitarnya. Sebagai bukti adalah masih didapati berbagai masalah tekanan terhadap kawasan hutan lindung, yang antara lain disebabkan oleh belum mantapnya lembaga pengelola serta tata batasnya, adanya persaingan kebutuhan lahan; letaknya yang berdekatan dengan pemukiman; hukum dan perundangan yang lemah; dan persepsi yang berbeda dari berbagai sektor (Anonim, 1998 dan Ginoga 2003).

Interaksi masyarakat dengan kawasan hutan lindung terjadi secara langsung dan tidak langsung. Pada masyarakat dengan kondisi sosial ekonomi rendah bentuk interaksi lebih banyak terjadi secara langsung seperti pengambilan kayu, getah, buah, pakan ternak, kayu bakar dan lain-lain. Sementara itu, bagi masyarakat dengan kondisi sosial ekonomi tinggi interaksi terjadi secara tidak langsung, seperti menjadi pemodal dalam usaha ilegal logging. Segala bentuk interaksi masyarakat dengan hutan lindung pada umumnya dipengaruhi oleh faktor permintaan hasil hutan dan kebutuhan finansial petani itu sendiri (Anonim, 2004).

Interaksi masyarakat dengan hutan lindung dalam beberapa kasus didapati memberikan kontribusi finansial terhadap pendapatan rumah tangga masyarakat yang hidup di sekitarnya. Di Jember misalnya (Anonim 2004) dengan memanfaatkan lahan hutan lindung untuk kegiatan agroforestri tanaman jagung dan buah-buahan maka pendapatan petani menjadi bertambah, dengan kontribusi $36 \%$ dari total pendapatan petani. Di samping itu, pemanfaatan hutan lindung untuk tanaman karet di Jambi juga memberikan kontribusi sebesar 63\% dari total pendapatan petani. Kedua bentuk interaksi di Jember dan Jambi tersebut menunjukan bahwa interaksi masyarakat dengan hutan lindung secara langsung dapat menambah pendapatan masyarakat di sekitarnya. Di pihak lain, kawasan hutan lindung juga dapat terpelihara jika pengawasan terhadap kegiatan pemanfaatan tersebut dilakukan secara ketat.

Salah satu propinsi di Sumatera yang masih cukup luas kawasan hutan lindungnya adalah Propinsi Sumatera Barat (Sumbar). Kawasan Hutan Lindung di Sumbar tercatat seluas 910.533 ha atau $21 \%$ dari total luas propinsi (4.289.800 ha). Angka prosentase ini 
menempatkan Propinsi Sumbar pada urutan kedua setelah Aceh (33\%) dalam urutan hutan lindung terluas di Sumatera (Ginoga, 2003). Namun, upaya pengelolaan hutan lindung di Sumbar masih banyak menghadapi masalah dengan masyarakat sekitarnya. Interaksi yang terjadi bukan saja dari masyarakat umum bahkan juga tumpang tindih dengan keperluan Instansi lain. Sejalan dengan perkembangan zaman, kini upaya pengelolaan hutan lindung dihadapkan pada era otonomi daerah yakni bagaimana caranya memberdayakan sumber alamnya sebagai sumber pendapatan asli daerah. Sejauh ini belum ada informasi yang memaparkan masalah partisipasi masyarakat dalam pengelolaan hutan lindung. Oleh karena itu diperlukan kajian yang bertujuan untuk mengetahui karakteristik sosial, tingkat pengetahuan dan partisipasi masyarakat dalam upaya pengelolaan hutan lindung di Kabupaten Pasaman, Propinsi Sumatera Barat.

\section{BAHAN DAN METODA}

\section{A. Lokasi dan Waktu}

Pasaman merupakan salah satu kabupaten di Propinsi Sumbar yang memiliki kawasan hutan yang cukup luas dan luas hutan lindungnya tercatat 289.480 ha atau 36,95\% dari total kawasan hutan yang ada serta tersebar hampir pada semua kecamatan Gambaran fisiografis wilayah pasaman adalah cukup bervariasi, dari datar hingga bergunung-gunung. Titik terendah terletak di Kec. Sungai Beremas ( $5 \mathrm{~m} \mathrm{dpl}$ ) dan tertinggi Gunung Talamau $(2.913 \mathrm{~m}$ dpl) di Kec. Talamau. Sedangkan jenis-jenis tanah yang terdapat di wilayah ini antara lain: Latosol, Podsolik Merah Kuning, Andosol (tanah hitam), Podsolik Coklat, Litosol dan Regosol (Anonim, 2001). Penelitian dilakukan di Kawasan Hutan Lindung Sumpur (luas 122.493 ha) dan Hutan Alahan Panjang (36.919 Ha); dengan lokasi nagari di Padang Matinggi (Kecamatan Rao) yang berbatasan dengan HL Sumpur dan Nagari Binjai (Kecamatan Tigo Nagari) yang berbatasan dengan Hutan Alahan Panjang. Pelaksanaan dilakukan pada bulan Juli - September 2004.

\section{B. Obyek, Bahan dan Alat}

Obyek penelitian ini adalah penduduk/masyarakat yang bertempat tinggal di Nagari Padang Matinggi (Kecamatan Rao) dan Nagari Binjai (Kecamatan Tigo Nagari) sedangkan bahan dan peralatan yang digunakan antara lain yaitu bahan quisioner, alat tulis, tape recorder, kaset, kamera photo, dan perlengkapan lapangan.

\section{Prosedur Pengumpulan Data}

Data yang dikumpulkan terdiri dari data sekunder dan data primer. Data sekunder berasal dari laporan Dinas kehutanan setempat, Bapeda Pasaman, laporan pengusaha pengguna jasa hutan lindung (PDAM), data statistik desa, kecamatan dan kabupaten. Sedangkan data primer dikumpulkan dengan cara pengamatan langsung di lapangan, yakni di Nagari Binjai, Kecamatan Tigo Nagari, Pasaman sebagai sampel desa yang menolak kegiatan proyek reboisasi; dan Nagari Padang Matinggi, Kecamatan Rao, sebagai desa yang menerima proyek reboisasi. Untuk mengetahui kondisi partisipasi masyarakat dari dua nagari yang terpilih dilakukan pengumpulan data dengan wawancara dan pengisian dan diskusi kepada 60 responden yang diambil secara acak; masing-masing 30 Kepala Keluarga untuk setiap nagari. 


\section{Pengolahan Data}

Data hasil pengamatan kemudian dianalisis secara deskripsi guna mendapatkan karakteristik kondisi social, pengetahuan dan tingkat dan partisipasi masyarakat dalam upaya pengelolaan hutan lindung. Digunakan analisis tabulasi untuk melihat hubungan tingkat partisipasi masyarakat dengan kondisi sosial dan program pengelolaan hutan lindung yang dilakukan.

\section{HASIL DAN PEMBAHASAN}

\section{A. Karakteristik Sosial Ekonomi Responden}

\section{Umur dan Asal}

Usia responden yang paling rendah adalah 25 tahun baik di Padang Matinggi maupun di Binjai, sedangkan usia tertinggi tercatat 70 tahun di Nagari Binjai dan 56 tahun di Nagari Padang Matinggi. Dari usia ini terlihat bahwa responden minimal sudah berusia 25 tahun dan maksimal 70 tahun, sehingga sudah terdapat kebiasaan untuk menentukan mana yang benar dan salah dalam pengelolaan kawasan hutan. Dalam ajaran Islam seseorang sudah dianggap dewasa jika sudah mentruasi (biasanya usia 14 tahun) dan laki-laki biasanya berusia 16 tahun. Dengan demikian, para responden terdiri dari anggota masyarakat dewasa sehingga dapat memberikan penilaian benar atau salah, baik dan buruk sesuai dengan sistem nilai dari lingkungan sosial budayanya.

Sebagian besar responden di Padang Matinggi berusia 26 - 35 tahun (43,3\%), diikuti dengan usia 36 - 40 tahun (33,3\%). Demikian juga halnya di Binjai kelas usia 26 - 35 tahun dan 36 - 40 tahun lebih dominan dibanding dengan usia lain. Hal ini menunjukkan bahwa responden pada kedua Nagari kebanyakan masih berusia produktif. Karakter umur responden selanjutnya dapat dilihat pada Table (1).

Tabel 1. Variasi Usia Responden

Table 1. Respondent Age Variation

\begin{tabular}{|c|c|c|c|c|}
\hline \multirow{2}{*}{$\begin{array}{c}\text { Umur (Tahun) } \\
\text { Age (Year) }\end{array}$} & \multicolumn{2}{|c|}{$\begin{array}{c}\text { Nagari Padang Matinggi } \\
\text { (Padang Matinggi Village) }\end{array}$} & \multicolumn{2}{c|}{$\begin{array}{c}\text { Nagari Binjai } \\
\text { (Binjai Village) }\end{array}$} \\
\cline { 2 - 5 } & $\mathrm{N}$ & $\%$ & $\mathrm{~N}$ & $\%$ \\
\hline$? 25$ & 2 & 6,7 & 4 & 13,3 \\
\hline $26-35$ & 13 & 43,3 & 9 & 30,0 \\
\hline $36-45$ & 10 & 33,3 & 6 & 20,0 \\
\hline $46-55$ & 4 & 13,3 & 2 & 6,7 \\
\hline$>56$ & 1 & 3,3 & 30 & 100,0 \\
\hline Total (total) & 30 & 100,0 & & 9 \\
\hline
\end{tabular}

Sumber (Source): Diolah dari data primer September 2004 (From primary data in September 2004) $\mathrm{n}=$ jumlah responden (number of respondent) 
Seluruh responden di Padang Matinggi adalah warga asli penduduk setempat. Sedangkan di Binjai sebagian besar $21 \mathrm{KK}(70,0 \%)$ adalah penduduk setempat, dan sisanya 9 KK $(30,0 \%)$ berasal dari tempat lain. Besarnya angka responden sebagian penduduk asli menunjukan kemungkinan besarnya adat kebiasaan setempat dalam merespon pengelolaan hutan lindung di sekitar nagari mereka.

\section{Mata Pencaharian dan Pendapatan}

Berdasarkan mata pencaharian dan pendapatan terlihat bahwa responden kebanyakan berusaha di sektor pertanian, seperti dalam Tabel (2). Semua responden di Padang Matinggi bermatapencaharian utama sebagai petani; sebagai usaha sampingan terdapat juga yang berusaha sebagai tukang, buruh, berdagang, dan lain-lain.

Tabel 2. Mata pencaharian dan pendapatan responden

Table 2. Occupation and Income

\begin{tabular}{|c|c|c|c|c|c|c|c|c|c|c|}
\hline \multirow{2}{*}{\multicolumn{2}{|c|}{$\begin{array}{c}\text { Mata Pencaharian } \\
\text { (Occupation) }\end{array}$}} & \multicolumn{2}{|c|}{$\begin{array}{l}\text { Padang } \\
\text { Matinggi }\end{array}$} & \multicolumn{2}{|c|}{ Binjai } & \multirow{2}{*}{$\begin{array}{c}\text { Pendapatan } \\
\quad(\text { Income }) \\
(\mathrm{Rp}) \times 1000\end{array}$} & \multicolumn{2}{|c|}{$\begin{array}{l}\text { Padang } \\
\text { Matinggi }\end{array}$} & \multicolumn{2}{|c|}{ Binjai } \\
\hline & & $\mathrm{N}$ & $0 \%$ & $n$ & $0 \%$ & & n & $0 \%$ & $n$ & 0 \\
\hline \multirow{2}{*}{$\begin{array}{l}\text { Utama } \\
\text { (Pimary) }\end{array}$} & $\begin{array}{c}\text { Tani } \\
\text { (Farmer) }\end{array}$ & 30 & 100 & 29 & 96,7 & $<500$ & \multirow{2}{*}{15} & \multirow{2}{*}{50,0} & \multirow{2}{*}{17} & \multirow{2}{*}{56,7} \\
\hline & $\begin{array}{l}\text { Non Tani } \\
\text { (Non farmer) }\end{array}$ & 0 & 0 & 1 & 3,3 & \multirow{2}{*}{$500-1000$} & & & & \\
\hline \multirow{4}{*}{$\begin{array}{l}\text { Sampingan } \\
\text { (Secundary) }\end{array}$} & Tukang & 2 & 6,7 & 0 & 0 & & \multirow[b]{2}{*}{14} & \multirow[b]{2}{*}{46,7} & \multirow[b]{2}{*}{11} & \multirow[b]{2}{*}{36,7} \\
\hline & $\begin{array}{l}\text { Buruh } \\
\text { (Labour) }\end{array}$ & 2 & 6,7 & 3 & 10,0 & \multirow{3}{*}{$>1000$} & & & & \\
\hline & Dagang & 2 & 6,7 & 1 & 3,3 & & \multirow{2}{*}{1} & \multirow{2}{*}{3,3} & \multirow{2}{*}{2} & \multirow{2}{*}{6,7} \\
\hline & Lain-lain & 2 & - & 4 & 13,3 & & & & & \\
\hline
\end{tabular}

Sumber (Source): Diolah dari data primer September 2004 (From primary data in September 2004) $\mathrm{n}=$ jumlah responden (number of respondent)

Pendapatan responden dari usaha tani tercatat kurang dari Rp. 500.000,- baik di Padang Matinggi maupun di Binjai. Hanya 1 - 2 KK (6,7\%) yang berpendapatan di atas Rp 1.000.000,per bulan. Jika upah minimum regional Rp. 20.000,- per hari (atau Rp 600.000,-/bulan) maka sebagian besar responden berpendapatan di bawah nilai upah minimum.

\section{Luas Lahan dan Anggota Rumah Tangga}

Sebagai petani, semua responden baik di Padang Matinggi maupun di Binjai mempunyai lahan. Luas lahan yang dimiliki responden cukup bervariasi mulai dari paling sempit $1 / 4$ ha, hingga paling luas 5 ha. Luas sempitnya kepemilikan lahan responden tergantung pada cara pengelolaan dan variasi dalam penggunaan lahan apakah untuk kebun atau ladang. 
Tabel 3. Kepemilikan Lahan dan Anggota Rumah Tangga Responden

Table 3. Land Owner and Number of Family Respondent

\begin{tabular}{|c|c|c|c|c|c|c|c|c|c|}
\hline \multirow{2}{*}{$\begin{array}{l}\text { Luas } \\
\text { Lahan } \\
\text { (Land } \\
\text { wide) }\end{array}$} & \multicolumn{2}{|c|}{$\begin{array}{l}\text { Padang } \\
\text { Matinggi }\end{array}$} & \multicolumn{2}{|c|}{ Binjai } & \multirow{2}{*}{$\begin{array}{l}\text { Jumlah anggota rumah tangga } \\
\text { (Number of family) }\end{array}$} & \multicolumn{2}{|c|}{$\begin{array}{l}\text { Padang } \\
\text { Matinggi }\end{array}$} & \multicolumn{2}{|c|}{ Binjai } \\
\hline & $\mathrm{n}$ & $\%$ & $\mathrm{n}$ & $\%$ & & $\mathrm{n}$ & $\%$ & $\mathrm{n}$ & $\%$ \\
\hline$<0,5$ & 2 & 6,7 & 5 & 16,7 & \multirow{2}{*}{ ? 4 jiwa (person) } & \multirow{2}{*}{12} & \multirow{2}{*}{40,0} & \multirow{2}{*}{15} & \multirow{2}{*}{50,} \\
\hline $0,5-1$ & 19 & 63,7 & 14 & 46,7 & & & & & \\
\hline$>1$ & 9 & 30,0 & 11 & 36,7 & \multirow[b]{2}{*}{$>4$ jiwa (person) } & \multirow[b]{2}{*}{18} & \multirow[b]{2}{*}{60,0} & \multirow[b]{2}{*}{15} & \multirow[b]{2}{*}{50,0} \\
\hline Total & 30 & 100,0 & 30 & $\begin{array}{c}100 \\
0\end{array}$ & & & & & \\
\hline
\end{tabular}

Sumber (Source): Diolah dari data primer September 2004 (From primary data in September 2004) $\mathrm{n}=$ jumlah responden (number of respondent)

Sebagai keluarga petani maka lahan adalah sesuatu yang penting bagi responden. Meskipun semua responden memiliki lahan, akan tetapi apabila dikaitkan dengan jumlah rumah tangga maka terlihat bahwa anggota rumah tangga berjumlah lebih dari empat orang; lebih besar dari jumlah ideal program keluarga berencana nasional. Hal ini menunjukkan bahwa masih ada kekurangan kebutuhan lahan dari anggota rumah tangga sehingga ada kecenderungan masyarakat untuk menekan kawasan hutan di sekitar nagari seperti adanya kebun sawit dalam kawasan hutan lindung yang berdekatan dengan Nagari Binjai.

\section{Pendidikan dan Status Sosial}

Pendidikan responden bervariasi dari tidak sekolah sampai dengan tamat menengah sekolah tingkat atas (SMU). Hal ini berarti juga bahwa responden mengikuti masa pendidikan selama 0 tahun sampai 12 tahun. Berdasarkan Tabel (4) terlihat bahwa responden yang berpendidikan di atas atau lebih enam tahun lebih rendah dibandingkan yang berpendidikan sampai enam tahun (SD). Dengan demikian, pendidikan responden masih tergolong rendah. Hal ini dapat dimaklumi karena aksebilitas wilayah nagari dan jumlah sarana pendidikan termasuk masih sulit dijangkau dan sangat terbatas (lebih kurang $25 \mathrm{~km}$ dari ibu kota kabupaten).

Meskipun berpendidikan relatif rendah, responden kebanyakan mempunyai status sosial sebagai tokoh masyarakat antara lain sebagai "ninik mamak", cerdik pandai, maupun tokoh formal nagari. Dari Tabel (4) tergambar bahwa 56,7\% responden di Padang Matinggi termasuk tokoh, demikian juga di Binjai tercatat 50,0\% adalah tokoh masyarakat. Dengan demikian, ketokohan seseorang kebanyakan dipandang dari segi garis keturunan dan kepahamannya terhadap adat istiadat, walaupun seseorang itu hanya memiliki tingkat pendidikan formal yang rendah. 
Tabel 4. Pendidikan dan Status Sosial

Table 4. Education and Social Status

\begin{tabular}{|c|c|c|c|c|c|c|c|c|c|}
\hline \multirow{2}{*}{$\begin{array}{l}\text { Pendidikan } \\
\text { (Education) }\end{array}$} & \multicolumn{2}{|c|}{ Padang Matinggi } & \multicolumn{2}{|c|}{ Binjai } & \multirow{2}{*}{$\begin{array}{l}\text { Status sosial } \\
\text { (Social status) }\end{array}$} & \multicolumn{2}{|c|}{ Padang Matinggi } & \multicolumn{2}{|c|}{ Binjai } \\
\hline & $\mathrm{n}$ & $\%$ & $\mathrm{n}$ & $\%$ & & $\mathrm{n}$ & $\%$ & $\mathrm{n}$ & $\%$ \\
\hline ? 6 tahun (year) & 16 & 53,3 & 20 & 66,7 & Biasa (common) & 13 & 43,3 & 15 & 50,0 \\
\hline $\begin{array}{l}6 \text { tahun } \\
\text { (year) }\end{array}$ & 14 & 46,7 & 10 & 33,3 & Tokoh (leader) & 17 & 56,7 & 15 & 50,0 \\
\hline Total & 30 & 100,0 & 30 & 100,0 & Total & 30 & 100,0 & 30 & 100,0 \\
\hline
\end{tabular}

Sumber (Source): Diolah dari data primer September 2004 (From primary data in September 2004) $\mathrm{n}=$ jumlah responden (number of respondent)

\section{B. Pengetahuan Masyarakat Terhadap Hutan Lindung}

Pengetahuan terhadap adanya kawasan hutan lindung bagi masyarakat yang hidup di sekitarnya penting untuk diketahui. Ketidaktahuan terhadap kawasan dapat mendorong masyarakat melakukan aktivitas konsumtif sehingga dapat mengganggu kelestarian kawasan lindung. Kebanyakan responden mengetahui adanya kawasan hutan lindung di sekitar nagari. Lebih separuh dari total responden $(70,0 \%)$ menyatakan mengetahui adanya hutan lindung, sebanyak $26,7 \%$ tidak tahu dan hanya 3,3\% tidak berpendapat. Namun demikian, hampir semua responden menyatakan tidak mengetahui status kawasan hutan formal. Bagi mereka hutan adalah kawasan "rimbo" yang dapat diusahakan untuk kebun atau ladang. Dalam pandangan responden, hutan disekitar kampung adalah tanah ulayat yang dikuasai oleh para "datuk" sebagai personifikasi "ninik mamak" masyarakat adat.

Istilah hutan lindung tidak banyak diketahui, tetapi "Bosweschen" yang dari bahasa Belanda lebih dikenal daripada istilah hutan lindung, bahkan dalam kawasan hutan ulayat-pun tidak terdapat bagian yang perlu dilindungi. Siapa yang kuat (modal maupun tenaga) setelah mendapat restu "ninik mamak" boleh membuka hutan untuk diusahakan sebagai kebun atau lainnya. Di Padang Matinggi, keberadaan hutan lindung terlihat jelas dengan adanya tanaman reboisasi jenis Pinus merkusii. Meskipun demikian, tidak semua responden mengetahui bahwa kawasan tersebut adalah hutan lindung. Berbeda dengan di Binjai, kawasan hutan lindung tidak dapat di bedakan dengan kawasan hutan ulayat karena vegetasi tropis yang menutupinya tidak menunjukkan perbedaan yang signifikan. 
Table 5. Pengetahuan responden terhadap hutan lindung

Table 5. Respondent knowledge toward forest protection

\begin{tabular}{|c|c|c|c|c|c|c|c|c|}
\hline \multirow{2}{*}{$\mathrm{No}$} & \multirow{2}{*}{$\begin{array}{l}\text { Aspek Pengetahuan } \\
\text { (Knowledge aspects) }\end{array}$} & \multirow{2}{*}{$\begin{array}{l}\text { Respon } \\
\text { (Response) }\end{array}$} & \multicolumn{2}{|c|}{$\begin{array}{l}\text { Padang } \\
\text { Matinggi }\end{array}$} & \multicolumn{2}{|c|}{ Binjai } & \multicolumn{2}{|c|}{ Total } \\
\hline & & & $\mathrm{n}$ & $\%$ & $\mathrm{n}$ & $\%$ & $\mathrm{n}$ & $\%$ \\
\hline \multirow[t]{3}{*}{1.} & \multirow{3}{*}{$\begin{array}{l}\text { Mengatahui adanya } \\
\text { hutan lindung ((forest } \\
\text { protection present) }\end{array}$} & $\mathrm{Ya}(Y e s)$ & 20 & 66.7 & 22 & 73.3 & 42 & 70 \\
\hline & & tidak (No) & 10 & 33.3 & 6 & 20.0 & 16 & 26.7 \\
\hline & & $\begin{array}{l}\text { tidak } \\
\text { berpendapat } \\
\text { (No comment) }\end{array}$ & 0 & 0 & 2 & 6.7 & 2 & 3.3 \\
\hline \multirow[t]{3}{*}{2.} & \multirow{3}{*}{$\begin{array}{l}\text { Mengetahui batasnya } \\
\text { (Forest Protection boundary) }\end{array}$} & $\mathrm{Ya}(Y e s)$ & 12 & 40.0 & 17 & 56.7 & 29 & 48.3 \\
\hline & & tidak (No) & 18 & 60.0 & 12 & 40.0 & 30 & 50.0 \\
\hline & & $\begin{array}{c}\text { tidak } \\
\text { berpendapat } \\
\text { (No comment) }\end{array}$ & 0 & 0 & 1 & 3.3 & 1 & 1.7 \\
\hline \multirow[t]{3}{*}{3.} & \multirow{3}{*}{$\begin{array}{l}\text { Tahu fungsi hutan } \\
\text { lindung (Functions of } \\
\text { Forest Protection) }\end{array}$} & $\mathrm{Ya}$ (yes) & 24 & 80.0 & 26 & 86.7 & 50 & 83.3 \\
\hline & & tidak (No) & 6 & 20.0 & 4 & 13.3 & 10 & 16.7 \\
\hline & & $\begin{array}{c}\text { Tidak } \\
\text { berpendapat } \\
\text { (No comment) }\end{array}$ & 0 & 0 & 0 & 0.0 & 0 & 0 \\
\hline \multirow[t]{3}{*}{4.} & \multirow{3}{*}{$\begin{array}{l}\text { Lembaga pengelola } \\
\text { hutan lindung (Instution } \\
\text { of forest protection) }\end{array}$} & Mengetahui & 16 & 53.3 & 20 & 66.7 & 36 & 60.0 \\
\hline & & Tidak tahu & 8 & 26.7 & 8 & 26.7 & 16 & 26.7 \\
\hline & & $\begin{array}{c}\text { Tidak } \\
\text { berpendapat }\end{array}$ & 6 & 20.0 & 2 & 6.7 & 8 & 13.3 \\
\hline \multirow[t]{3}{*}{5.} & \multirow{3}{*}{$\begin{array}{l}\text { Dikelola baik (Good } \\
\text { management) }\end{array}$} & Ya (Yes) & 12 & 40.0 & 11 & 36.7 & 23 & 38.3 \\
\hline & & Tidak (No) & 8 & 26.7 & 11 & 36.7 & 19 & 3.7 \\
\hline & & $\begin{array}{c}\text { Tidak } \\
\text { berpendapat } \\
\text { (No comment) }\end{array}$ & 10 & 33.3 & 8 & 26.6 & 18 & 30.0 \\
\hline \multirow[t]{3}{*}{6.} & \multirow{3}{*}{$\begin{array}{l}\text { Pemanfaatan kayu } \\
\text { (logging activity) }\end{array}$} & Ya (Yes) & 0 & 0 & 19 & 63.3 & 19 & 31.7 \\
\hline & & Tidak (No) & 17 & 56.7 & 3 & 10.0 & 20 & 33.3 \\
\hline & & $\begin{array}{c}\text { Tidak } \\
\text { berpendapat } \\
\text { No comment }\end{array}$ & 13 & 43.3 & 8 & 26.7 & 21 & 35.0 \\
\hline \multirow[t]{2}{*}{7.} & \multirow{2}{*}{$\begin{array}{l}\text { Untung dan rugi adanya } \\
\text { hutan lindung (advantage } \\
\text { or disdvantage) }\end{array}$} & $\begin{array}{l}\text { Untung } \\
\text { (Advantage) }\end{array}$ & 13 & 43.3 & 3 & 10.0 & 16 & 26.7 \\
\hline & & $\begin{array}{c}\text { Rugi } \\
\text { (Disadvantage) }\end{array}$ & 17 & 56.7 & 27 & 90.0 & 44 & 73.3 \\
\hline \multirow[t]{3}{*}{8.} & \multirow{3}{*}{$\begin{array}{l}\text { Konversi hutan lindung } \\
\text { (forest convertion) }\end{array}$} & $\mathrm{Ya}(Y e s)$ & 21 & 70 & 23 & 76.7 & 44 & 73.3 \\
\hline & & Tidak (No) & 7 & 23.3 & 2 & 6.7 & 9 & 15.0 \\
\hline & & $\begin{array}{c}\text { Tidak } \\
\text { berpendapat } \\
\text { (No comment) }\end{array}$ & 2 & 6.7 & 5 & 16.7 & 7 & 11.7 \\
\hline
\end{tabular}

Sumber (Source): Diolah dari data primer September 2004 (From primary data in September 2004)

$\mathrm{n}=$ jumlah responden (number of respondent) 
Meskipun yang mengetahui keberadaan hutan lindung lebih banyak dari yang tidak, akan tetapi tidak semua responden mengetahui batasnya. Hanya 40,0\% di Padang Matinggi yang mengetahui batas berupa beton merah, dan 60,0\% tidak mengetahuinya. Hal ini terjadi karena jarak pemukiman dengan kawasan hutan lindung relatif jauh antara 2 - $10 \mathrm{~km}$. Berbeda dengan di Binjai, dimana yang mengetahui batas lebih besar dari yang tidak mengetahui (seperti dalam Tabel 5). Keseringan berinteraksi antara responden dengan kawasan hutan lindung di Binjai menyebabkan responden di nagari ini lebih banyak mengetahui batas hutan lindung. Di samping itu, tanda batas hutan di Binjai lebih banyak terlihat dibandingkan dengan di Padang Matinggi.

Sudah menjadi budaya setempat, terutama di Binjai, penggunaan hutan ulayat diprioritaskan untuk para anak cucu dan kemenakan dari pihak ibu. Pendatang yang "bersumando" termasuk yang diizinkan juga. Bagi pihak lain yang hendak menggarap hutan perlu mendapat izin dari "ninik mamak" (datuk). Kawasan hutan lindung dalam kawasan hutan ulayat menjadi perkara yang rancu dalam hal pengelolaan karena pada kawasan yang sama terdapat dua pihak pengelola, dalam hal ini adalah pemerintah dan para datuk. Hutan lindung bagi pemerintah adalah hutan yang perlu dijaga, sementara bagi datuk hutan adalah sumber alam cadangan untuk tempat berusaha anak-kemanakannya. Bagi warga, jika ada modal maka hutan ulayat (apakah berstatus hutan lindung) dapat diusahakan untuk berladang atau berkebun terutama jenis sawit.

Secara formal, sesuai Undang-Undang No. 41 Tahun 1999, hutan lindung berfungsi sebagai perlindungan sistem penyangga kehidupan untuk mengatur tata air mencegah banjir, mengendalikan erosi dan memelihara kesuburan tanah serta mencegah intrusi laut. Sehubungan dengan itu, di Padang Matinggi dan Binjai hanya empat fungsi yang secara realistik dapat terpenuhi dari hutan lindung terhadap masyarakat sekitarnya, yaitu: mengatur tata air, mencegah banjir, mengendalikan erosi dan memelihara kesuburan tanah. Pengetahuan responden terhadap fungsi hutan lindung terlihat cukup baik dimana 83,3\% dari total responden menyatakan mengetahui fungsinya. Namun kebanyakan responden hanya mengetahui satu fungsi (45,0\%) yakni sebagai kawasan untuk mencegah banjir, diikuti kemudian dengan mengetahui dua fungsi $(31,7 \%)$, selanjutnya dapat dilihat pada Tabel (6).

Walaupun responden kebanyakan mengetahui fungsi hutan lindung, terutama untuk mencegah banjir, namun demikian responden pada kedua nagari kebanyakan menyatakan rugi dengan adanya hutan lindung, masing-masing 56.7\% di Padang Matinggi dan 90,0\% di Binjai. Lahan semakin sempit sehingga tidak dapat bertani dan gangguan babi hutan (Sus sp) serta monyet (Macaca spp) adalah alasan utama mengapa responden menyatakan rugi dengan adanya hutan lindung. Hal ini selanjutnya terlihat jelas dari pandangan responden yang sebagian besar setuju (73,3\%) jika hutan lindung dikonversi menjadi areal usaha tani masyarakat. 
Tabel 6. Pengetahuan Terhadap Fungsi Hutan Lindung

Table 6. Knowledge of Forest Protection Function

\begin{tabular}{|c|c|c|c|c|c|c|}
\hline \multirow{2}{*}{$\begin{array}{l}\text { Fungsi hutan lindung } \\
\text { (Forest protection functions) }\end{array}$} & \multicolumn{2}{|c|}{ Padang Matinggi } & \multicolumn{2}{|c|}{ Binjai } & \multicolumn{2}{|c|}{ Total } \\
\hline & $\mathrm{n}$ & $\%$ & $\mathrm{n}$ & $\%$ & $\mathrm{n}$ & $\%$ \\
\hline $\begin{array}{l}\text { 1. Empat fungsi sbg pengatur tata air, } \\
\text { mencegah banjir, erosi, menjaga } \\
\text { kesuburan tanah (four function as } \\
\text { preventing flood, erosion, and soil } \\
\text { fertilization) }\end{array}$ & 0 & 0 & 0 & 0 & 0 & 0 \\
\hline $\begin{array}{l}\text { 2. Tiga fungsi sebagai pencegah banjir, } \\
\text { erosi, menjaga kesuburan tanah (three } \\
\text { function as preventing flood, erosion, and soil } \\
\text { fertilization). }\end{array}$ & 4 & 13.3 & 0 & 0 & 4 & 6.7 \\
\hline $\begin{array}{l}\text { 3. Dua fungsi sebagai pencegah banjir \& } \\
\text { erosi (Two function as preventing flood, and } \\
\text { erosion). }\end{array}$ & 11 & 36.7 & 8 & 26.7 & 19 & 31.7 \\
\hline $\begin{array}{l}\text { 4. Satu fungsi sebagai pencegah banjir } \\
\text { (only one function as preventing flood,) }\end{array}$ & 9 & 30.0 & 18 & 60.0 & 27 & 45.0 \\
\hline 5. Tidak tahu (not know) & 6 & 20.0 & 4 & 13.3 & 10 & 16.7 \\
\hline Total & 30 & 100.0 & 30 & 100.0 & 60 & 100.0 \\
\hline
\end{tabular}

Sumber (Source): Diolah dari data primer September 2004 (From primary data in September 2004) $\mathrm{n}=$ jumlah responden (number of respondent)

Pengetahuan terhadap lembaga pengelola hutan lindung memperlihatkan hasil yang beragam. Tabel (5) menunjukkan bahwa jumlah responden yang mengetahui lembaga pengelola hampir sama dengan yang tidak. Hal ini jelas terlihat di Binjai karena pengaruh "ninik mamak" terhadap tanah ulayat di kawasan hutan lindung lebih kuat dibandingkan dengan di Padang Matinggi. Kekuatan pengaruh "ninik mamak" ditambah lagi dengan kurangnya patroli petugas kehutanan menyebabkan lebih dari separuh responden menyatakan tidak kenal dengan lembaga pengelola hutan lindung. Lebih jauh dampak dari ketidaktahuan ini adalah masih banyak responden di Binjai (63,3\%) yang memanfaatkan hutan lindung untuk mengambil hasil kayu.

\section{Partisipasi dalam Pengelolaan Hutan Lindung}

Partisipasi masyarakat dalam pengelolaan hutan lindung dapat dilihat dari keikutsertaan mereka dalam program yang dilakukan Dinas Kehutanan Pasaman terhadap kawasan hutan lindung. Di samping itu, partisipasi juga dapat ditinjau dari aktivitas bersifat swadaya yang dilakukan oleh masyarakat terhadap hutan lindung. Berdasarkan wawancara dengan pihak Dinas Kehutanan Pasaman (2004) diketahui adanya program penghijauan dan reboisasi di Padang Matinggi dan Binjai baik dalam kawasan hutan lindung maupun di luar kawasan hutan lindung. 
Tabel 7. Partisipasi responden dalam pengelolaan hutan lindung Table 7. Partisipation toward forest protection managament

\begin{tabular}{|c|c|c|c|c|c|c|}
\hline \multirow{2}{*}{ No } & \multirow{2}{*}{ Aspek Partisipasi (Partisipation aspect) } & \multirow{2}{*}{ Responden } & \multicolumn{2}{|c|}{ Padang Matinggi } & \multicolumn{2}{|c|}{ Binjai } \\
\hline & & & $\mathrm{N}$ & $\%$ & $\mathrm{n}$ & $\%$ \\
\hline \multirow[t]{2}{*}{1.} & \multirow{2}{*}{$\begin{array}{l}\text { Mengetahui adanya program reboi - } \\
\text { sasi/penghijauan (know to reforestation/ } \\
\text { replanting program) }\end{array}$} & Ya (yes) & 30 & 100.0 & 11 & 36.7 \\
\hline & & Tidak (no) & 0 & 0 & 19 & 63.3 \\
\hline \multirow[t]{2}{*}{2.} & \multirow{2}{*}{$\begin{array}{l}\text { Menerima reboisasi/penghijauan } \\
\text { (Accept to reforestation/ replanting } \\
\text { program) }\end{array}$} & Ya (yes) & 30 & 100.0 & 0 & 0 \\
\hline & & Tidak (no) & 0 & 0 & 30 & 100.0 \\
\hline \multirow[t]{2}{*}{3.} & \multirow{2}{*}{$\begin{array}{l}\text { Terlibat dalam kegiatan reboisasi/ } \\
\text { penghijauan (fallow in reforesta- } \\
\text { tion/ replanting program) }\end{array}$} & Ya (yes) & 18 & 60.0 & 0 & 0 \\
\hline & & Tidak (no) & 12 & 40.0 & 30 & 100.0 \\
\hline \multirow[t]{4}{*}{4.} & \multirow{2}{*}{$\begin{array}{l}\text { Keterlibatan dalam (fallow in): } \\
\text { a. Perencanaan (Planning) }\end{array}$} & Ya (yes) & 6 & 20.0 & 0 & 0 \\
\hline & & Tidak (no) & 24 & 80.0 & 30 & 100.0 \\
\hline & \multirow[t]{2}{*}{ b. evaluasi (Evaluation) } & Ya (yes) & 3 & 10.0 & 0 & 0 \\
\hline & & Tidak (no) & 27 & 70.0 & 30 & 100.0 \\
\hline \multirow[t]{2}{*}{5.} & \multirow[t]{2}{*}{ Kegiatan swadaya (Self program) } & $\mathrm{Ya}$ (yes) & 11 & 36.7 & 0 & 0 \\
\hline & & Tidak (no) & 19 & 63.3 & 30 & 100.0 \\
\hline
\end{tabular}

Sumber (Source): Data primer September 2004 (From primary data in September 2004) $\mathrm{n}=$ jumlah responden (number of respondent)

Program reboisasi yang dilakukan pada tahun 1980-an telah berhasil dengan baik di Padang Matinggi. Hasil kegiatan tersebut telah menghijaukan kawasan yang tadinya kritis, sehingga menimbulkan persepsi yang positif bagi masyarakat terhadap upaya pengelolaan hutan lindung. Dari Tabel (6) terlihat bahwa responden di Padang Matinggi semuanya mengetahui dan menerima upaya reboisasi dan penghijauan pada hutan lindung dan lahan adat. Bahkan tokoh-tokoh nagari ini secara aktif mendatangi kantor Dinas Kehutanan Pasaman dengan maksud agar kegiatan GERHAN (Gerakan Rehabilitasi Hutan dan Lahan) pada tahun 2003 dan 2004 dilakukan di Nagari mereka. Matinggi. Permintaan ini disambut baik oleh pihak Dinas Kehutanan sehingga pada tahun 2003 dan 2004 proyek GERHAN di lakukan di Padang Matinggi, setelah sebelumnya ditolak di Binjai.

Berbeda dengan di Binjai, semua responden tidak dapat menerima GERHAN karena berbagai alasan yang bersifat sosio-ekologis. Meskipun terdapat juga yang mengetahui program GERHAN, tetapi mereka sepakat untuk menolaknya. Oleh karena itu pula tidak ada responden yang terlibat aktif pada kegiatan tersebut. Sementara di Padang Matinggi tercatat $18 \mathrm{KK}(60 \%)$ terlibat dalam kegiatan reboisasi, dan hanya $40 \%$ yang tidak. Sebenarnya masih banyak yang berkeinginan ikut, akan tetapi target peserta yang diinginkan dalam program kegiatan tersebut sudah mencukupi. 
Menurut Terra, Malik dan Wali Padang Matinggi (2004), sebenarnya proyek GERHAN di Kabupaten Pasaman pada Pebruari 2004 memilih lokasi di Binjai. Tetapi, selama hampir dua bulan dengan tujuh kali pertemuan antara Dinas Kehutanan dan tokoh masyarakat Binjai tidak didapati keputusan yang bulat. Bahkan, sebaliknya masyarakat menolak proyek tersebut dengan "Deklarasi Pernyataan Penolakan" yang ditandatangani oleh semua "Datuk" (12 orang) dan 1 orang anggota masyarakat biasa. Paling tidak terdapat empat alasan yang menjadi motivasi penolakan tersebut. Pertama lahan adat yang digunakan perlu diganti dengan "bungo sirih" semacam uang ganti rugi dari penggunaan lahan ulayat. Dan "bungo sirih" ini dikuasai oleh "ninik mamak" yang penggunaannya berada dalam wewenang "datuk". Kedua, adanya ketakutan masyarakat yang merasa tidak akan dapat lagi mengusahakan lahan dimana tanaman GERHAN ditanam. Menurut informasi yang mereka terima, setelah tanaman besar maka areal tidak dapat diusahakan lagi. Padahal menurut Petugas Dinas Kehutanan informasi tersebut tidaklah benar. Lahan-lahan yang akan ditanam adalah kawasan hutan lindung, yang sudah berubah menjadi areal pertanian (kebun dan sawah). Ketika areal ini dibuat patok tanda batas maka masyarakat tidak dapat menerimanya. Ketiga, adanya keyakinan masyarakat bahwa di sekitar nagari tidak ada hutan lindung, yang ada hanya hutan ulayat. Oleh karena itu, tidak perlu dibuat reboisasi. Keempat, adanya provokator yang tidak menginginkan masuknya proyek GERHAN karena adanya kegiatan untuk memanfaatkan hutan dalam bentuk illegal logging dan menginginkan agar tanah ulayat lebih baik digunakan untuk untuk kebun sawit daripada untuk proyek penghijauan.

Sebaliknya, masyarakat Nagari Padang Matinggi menyatakan kesiapan agar wilayahnya dijadikan lokasi GERHAN maka direncanakan pertemuan di Muara Cibadak, Padang Matinggi dengan pihak Dinas Kehutanan Pasaman. Pada saat pertemuan terlihat animo masyarakat sangat tinggi karena dari \pm 120 yang direncanakan hadir, ternyata yang datang lebih 300 orang. Hampir semua tokoh penting hadir dan sepakat menerima proyek GERHAN dengan alasan : pertama, reboisasi pernah dilaksanakan di Padang Matinggi pada tahun 1976-1984. Hasilnya padang ilalang yang luasnya \pm 10.000 ha telah berubah menjadi hutan tusam sehingga banyak manfaat yang diterima masyarakat seperti udara segar dan sumber air. Lebih dari itu, hutan tusam sekarang sudah dapat dipanen getahnya. Setiap $1 \mathrm{~kg}$ getah pinus maka nagari mendapat fee sebesar Rp. 50,- (5\%) karena harga $1 \mathrm{~kg}$ getah = Rp. 1.000,-. Pengalaman reboisasi pinus tahun 1976-1984 inilah sangat mengesankan bagi masyarakat. Kedua, tahun 1997 adalagi proyek padat karya dari Dinas Hutbun yang membagi bibit karet (Havea braseliensis) sehingga tertanam \pm 25 ha. Kini tanaman karet tersebut juga sudah menghasilkan getah. Ketiga, adanya lahan kritis yang cukup luas di wilayah nagari. Persoalan lahan kritis ini sudah terpikirkan, bahkan sudah diusulkan agar dihijaukan. Keempat, adanya lapangan kerja buat masyarakat dengan bekerja sebagai tenaga lapangan yang upahnya Rp. 20.000,-/ orang/hari.

Berdasarkan empat alasan tersebut di atas maka proyek GERHAN di Padang Matinggi mendapatkan respon sangat positif dari masyarakat. Lebih dari 60\% masyarakat turut berpartisipasi dalam program tersebut. Bukti lain adalah masyarakat tidak curiga pada program ini, padahal program ini sangat dicurigai oleh masyarakat di Binjai. Walaupun aktif berpartisipasi dalam kegiatan GERHAN namun partisipasi tersebut hanya sebatas pelaksana untuk mendapatkan upah. Dari Tabel (6) terlihat hanya 20,0\% menyatakan ikut dalam perencanaan proyek dan hanya 10,0\% yang turut dalam evaluasi. Dengan demikian, partisipasi masyarakat di Padang Matinggi terlihat dominan dalam kegiatan pelaksanaan untuk mendapatkan upah kerja, sedangkan di Binjai tidak ada partisipasi sama sekali. 


\section{KESIMPULAN DAN SARAN}

1. Pada umumnya masyarakat telah mengetahui adanya hutan lindung di sekitar pemukimannya. Namun demikian, kawasan hutan lebih dikenal dengan nama "boswescen" daripada hutan lindung sehingga perlu sosialisasi untuk meluruskan pengertian tersebut ke arah yang sebenarnya. Lebih lanjut sebagian besar responden mengetahui batas kawasan hutan lindung karena adanya interaksi yang intensif dari masyarakat dalam memasukinya. Di samping itu, adanya tanaman reboisasi juga efektif untuk meningkatkan pengetahuan masyarakat terhadap batas kawasan. Berkaitan dengan hal ini maka batas berupa beton atau tanaman reboisasi penting dipelihara dan juga segera membuat batas baru pada lokasi yang rawan gangguan.

2. Sebagian besar karakter masyarakat yang hidup di sekitar hutan lindung adalah masyarakat asli yang lahir dan dewasa di desanya, berusia produktif, bekerja sebagai petani dengan pendapatan rata-rata Rp 500.000 - Rp 1.000.000/bulan, berpendidikan rendah, mempunyai jumlah anggota keluarga lebih dari dua orang, dan rata-rata memiliki lahan. Kehidupan sosial mereka diwarnai oleh batasan-batasan adat yang ketat dengan dominasi peran dari lembaga "ninik mamak". Pandangan masyarakat terhadap hutan dipengaruhi oleh pandangan "ninik mamak". Jika pandangan "ninik mamak" positif maka besar kemungkinan pandangan masyarakat terhadap hutan pun akan positif. Sebaliknya akan negatif jika pandangan "ninik mamak" negatif.

3. Partisipasi masyarakat dapat meningkat jika kegiatan proyek dalam hutan lindung memberikan keuntungan finansial bagi masyarakat. Di Padang Matinggi partisipasi lebih baik dibandingkan dengan di Nagari Banjai karena di Padang Matinggi kegiatan proyek reboisasi telah nyata memberikatan peningkatan pendapatan keluarga. Sedangkan di Binjai masyarakat belum mendapatkan pengalaman kegiatan reboisasi sehingga tidak dapat secara langsung mendukung kegiatan pembangunan kawasan hutan lindung.

\section{DAFTAR PUSTAKA}

Anonim, 1998. Buku Pedoman Kehutanan Indonesia. Departemen Kehutanan dan Perkebunan Republik Indonesia, Badan Penelitian dan Pengembangan Kehutanan dan Perkebunan, Jakarta.

Anonim, 1999. Penyempurnaan Data Dasar Kawasan Lindung Serta Perencanaan Teknis Pengelolaan Cagar Alam dan Daerah Penyangga. Proyek Bantuan Pengelolaan Kawasan Lindung DATI I Sumatera Barat. Dinas Kehutanan Sumatera Barat. Padang.

Anonim, 2004. Laporan Tahunan Hasil Penelitian Tahun 2003 Buku II. Badan Litbang Kehutanan, Departemen Kehutanan. Jakarta. Hal 117-123.

Bahruni. 1992. Perencanaan Proyek Pengembangan Manfaat Intangible Sumberdaya Hutan. Laboratorium Politik Ekonomi dan Sosial Kehutanan. Jurusan Manajemen Hutan. Fakultas Kehutanan. Institut Pertanian Bogor.

Ginoga, K.L., 2003. Kajian Sosial Ekonomi Pengelolaan Hutan Lindung. Proposal Penelitian Terpadu (PPT). Pusat Penelitian dan Pengembangan Sosial Budaya dan Ekonomi 
Kehutanan, Badan Penelitian dan Pengembangan Kehutanan, Depertemen Kehutanan. Bogor.

Singarimbun, M. dan Sopian E., 1989. Metode Penelitian Survey. LP3ES, Jakarta.

Terra, Malik dan Wali Nagari Padang Matinggi (2004), Wawancara Pribadi. Lubuk Sikaping, Pasaman.

Undang-undang No. 41 tahun 1999 tentang Kehutanan. 